\title{
APPLICATION OF LOW ENERGY ELECTRON BEAMS FOR TECHNOLOGY AND MEDICINE
}

\author{
${ }^{1}$ B. Bogdanovitch, V. Senioukov, MEPhI, Moscow, Russia \\ A. Koroliov, K. Simonov, State Concern "Istok", Fryazino, Russia
}

\begin{abstract}
Though the low energy electrons $(160-200 \mathrm{keV})$ do not penetrate deep into the material's surface the application of such beams can be effective enough in some technological processes, i.e. for processing the materials surface or for realizing processes in gases. For researching of low energy beams influence on the materials it was created a special experimental installation based on a powerful electron gun with wide rectangular output window. A number of different polymer materials were processed in this installation and it was obtained an increasing of durability, limit of elasticity, wearability and thermoresistivity in number of times. Its important to note that depth of materials properties changes is much higher then the electron penetration depth. Probably it is due to concurrent action of electron beam and intensive $\mathrm{x}$-ray irradiation arising from the output window foil. Due to their properties such beams can be effectively used in agriculture and medicine also.
\end{abstract}

\section{APPLICATION OF ELECTRON BEAMS}

\subsection{Interaction of Electrons with Substance}

The accelerated electrons, getting in substance, electrostatically interact with electrons and nucleuses of atoms. The most part of the beam energy is spent for interaction with orbital electrons. The primary particle transfers them a part of their energy, owing to what they pass to orbits of greater radius (excitation) or come off atom (ionization). The average energy spent on formation of one pair of ions (an energy of ionization), practically does not depend on a primary electrons energy and makes for many substances $\sim 30 \mathrm{eV}$. Potential of ionization of simple molecules is close to $10 \mathrm{eV}$. Other two thirds of a primary particle energy are spent for excitation and other processes. If the energy of primary electrons makes 100$200 \mathrm{keV}$, the complete loss of an energy occurs at the expense of repeated collisions.

The depth of electrons penetration in substance (for energies from $10 \mathrm{keV}$ up to $1 \mathrm{MeV}$ ) can be defined with the help of expression:

$$
\lambda_{\mathrm{m}}=6,7 \cdot 10^{-11} \mathrm{~W}^{5 / 3} / \rho,
$$

where $1_{\mathrm{m}}$ is a depth of electrons penetration in material $[\mathrm{cm}] ; \mathrm{W}$ - electrons energy $[\mathrm{eV}] ; \mathrm{r}$ - substance density $\left[\mathrm{g} / \mathrm{cm}^{3}\right]$.

The diagram of electrons with energy 160-200 keV penetration depth v.s. substance density is given on Fig.1. From this diagram it follows, that low energy electron beams can be most effectively used in gas environments, where their penetrating ability makes about $15-20 \mathrm{~cm}$. Besides, the electron beams with small penetrating ability are necessary for processing surface layers of products in order to prevent the beam influence on internal areas that my be inadmissible.

\subsection{Application of Electron Beams}

At passage in substance the primary electrons cause breaks of molecular links. The formed charged and neutral splinters of molecules have high chemical activity and quickly react with each other and with other molecules, owing to what the molecular structure of a material changes and the substance with new properties is

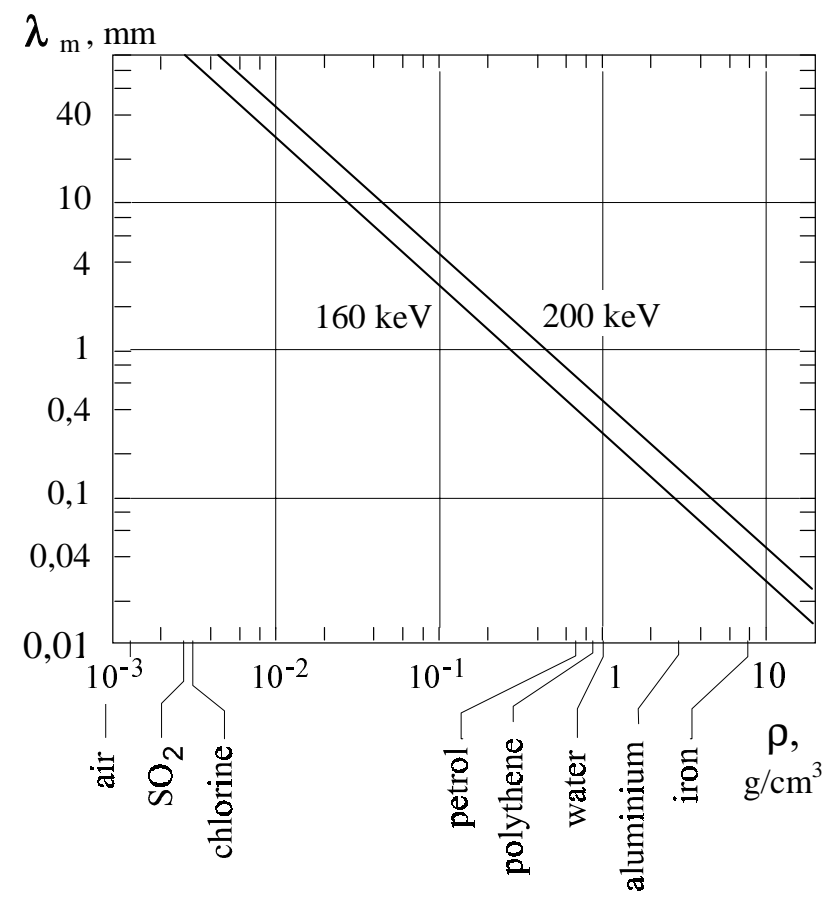

Figure 1: Penetration length $\lambda_{\mathrm{m}}$ for 160 and $200 \mathrm{keV}$ electrons in substances with different density $\rho$.

\footnotetext{
${ }^{1}$ E-mail: bogdan@uni.mephi.ru
} 
formed. The high chemical activity of reacting particles makes possible a realization of radiation-chemical reactions even at very low temperatures. Thus also disappears a necessity of the initiators and catalysts use, that allows to create a high cleanliness materials.

\subsection{Radiating modification of polymers}

Radiating polymerization processes are rather effective energetically and can be carried out at temperature, optimum for molecular circuits growth. The polymers properties modification by radiation is caused by processes of polymerization (seaming) and destruction of molecules. The radiation can stimulate both processes of molecule polymerization and one-dimensional polymer modifying in spatial one by intermolecular links creating. These links reduce displacement of molecules at mechanical influences, that results in increase of a limit of elasticity and reduction of plastic deformations. It decreases a material deterioration (in 2-4 times) and the range of working temperatures extends. The typical changes of the basic mechanical and operational characteristics of some plastics and rubbers used, in particular, for manufacturing of automobile linings, shock-absorbers etc. are given in Tables 1 and 2. The similar results can be got for processing other polymers.

The radiating processing of photo-polymers, used in polygraph, allows to increase their durability and thermoresistivity in a number of times. For some applications it makes it possible to use processed photo-polymer form instead metal ones.

Typical changes of material properties caused by destruction of molecules are the increase of substance solubility and reduction of its viscosity. The destruction process at irradiation in water solutions prevails for many polymers, that is due to participation in reactions the water radiolize products. Using of this process for industrial and household wastewater clearing is of practical interest. First of all it concerns to neutralization of synthetic superficial-active substances used for abstergents manufacturing. At water radiating processing its sterilization is taking place as well.

One of the most widespread technologies using combined radiating processes is radiating hardening of lacker and paint coverings. Unlike the traditional technology, radiating polymerization lasts less than 1 second and does not require additional polishing. Such coverings have high mechanical durability, chemical- and thermoresistivity. With the help of these processes thin layered plastics, foiled dielectrics, dielectric covering on various substrates, multilayer boards can be created also. Radiating hardening is used in a magnetic tape manufacturing, in a polygraph industry and some other processes. In hardening of a typographical paint on banknotes the positive results are received.
Table 1: Typical changes of materials parameters after radiation treating.

\begin{tabular}{|l|c|c|c|c|}
\hline \multirow{2}{*}{ Material } & \multicolumn{4}{|c|}{ Parameters changing (increasing) } \\
\cline { 2 - 5 } & $\begin{array}{c}\text { Module of } \\
\text { elasticity }\end{array}$ & $\begin{array}{c}\text { Elastic } \\
\text { limit }\end{array}$ & $\begin{array}{c}\text { Wear- } \\
\text { ability }\end{array}$ & $\begin{array}{c}\text { Tempe- } \\
\text { rature, }{ }^{\circ} \tilde{N}\end{array}$ \\
\hline Caprolon & 1,0 & 3 & $1,6-1,7$ & - \\
\hline Rubber & $1,2-1,3$ & $5-6$ & - & - \\
\hline $\begin{array}{l}\text { Silicon } \\
\text { rubber }\end{array}$ & - & - & - & -60 \\
\hline Polyuretan & - & - & $1,7-2$ & - \\
\hline
\end{tabular}

Table 2: Operating temperature for different regimes

\begin{tabular}{|l|c|c|c|}
\hline \multirow{2}{*}{$\begin{array}{c}\text { Polythene } \\
\text { seamed method }\end{array}$} & \multicolumn{3}{|c|}{$\begin{array}{c}\text { Operating temperature for different } \\
\text { time regimes, }{ }^{\circ} \tilde{\mathrm{N}}\end{array}$} \\
\cline { 2 - 4 } & Long lasting & $\begin{array}{c}100 \\
\text { h/year }\end{array}$ & Shortly \\
\hline chemically & 90 & 130 & 250 \\
\hline radiationally & 150 & 200 & 300 \\
\hline
\end{tabular}

\subsection{Radiating technological processes in gases, oil and petroleum processing}

The processes of this type basically are used for clearing gases of the industrial enterprises of harmful impurity. The greatest danger represents sulfur dioxide $\mathrm{SO}_{2}$ and nitrogen oxides $\mathrm{NO}_{\mathrm{X}}$. The radiating method with addition of ammonia allows to fix up to $80 \% \mathrm{NO}_{\mathrm{x}}$ and up to $90 \%$ $\mathrm{SO}_{2}$. The firm particles are formed which are grasped by electrostatic filter. Process of clearing from sulfurhydrogen $\mathrm{H}_{2} \mathrm{~S}$ can be carried out similarly.

The radiating influence on petroleum and oil allows to increase essentially a useful product output at cracking. Two kinds of cracking are applied now: thermal and catalyzed. These processes have the certain lacks both. Application of an electron beam as the chemical catalyst is effective enough, as it has volumetric action while the usual chemical catalyst - only superficial. Besides there is no necessity of catalyst regeneration.

\subsection{Beams application for medicine and food- processing}

The application of radiating technologies in medicine and food-processing industry is based on biological action of radiation. Depending on a doze of an irradiation the various results are possible: stimulation of development, genetic changes, sterilization, delay of growth, chemical decomposition. The sterilization of medical materials and tools is the first radiating process mastered in industrial scales. One of possible directions of foodstuff radiating sterilization is the products processing after their culinary treatment. After such processing the product can be stored at room temperature during several months without any preserves. In agriculture the radiating technologies are applied for a grain disinsection, growth stimulation before 
crop, germination delay at storage etc. The irradiation doze of 50-150 Gr prevents potatoes from germination within 10-15 months at usual storage temperatures. For electrons this doze can be increased up to $300-500 \mathrm{Gr}$ and storage time will be longer for 2-3 months. An onions can be exposed to the same processing. Advantages of radiating processing before chemical: absence of products impurity, smaller cost, line processing.

\section{SPECIALISED ELECTRON GUN FOR RADIATING PROCESSES}

\subsection{The Electron Gun Construction}

The electron gun of a modular type is a kind of a direct action particle accelerator (see Fig.2). Electron beam is extracting out through a thin foil and the irradiation of products is made over a large enough area without application of any additional devices.

The developed gun, unlike similar ones, is compact, durable, does not require vacuum pumps and provides good repeatability of characteristics. The large irradiation fields can be received by combining a number of guns. Several complex scientific and technological problems was solved for electron gun development. The main problems are: creation of a tight and reliable output window, development of electron-optical system with good beam distribution over an output window, creation of effective and reliable cathodes, and technology of gun assembling with a necessary vacuum maintenance.

The output window design is one of the basic problems in electron gun creation. A small density material should be used for foil and it must be as thin as possible. The best results (for mechanical, vacuum and thermal properties) were achieved using a titanium foil $30 \mu \mathrm{m}$ thick. With the help of diffuse welding the foil is welded on basic copper lattices, which besides carry out a cooler role. The welding is carried out in vacuum at high temperature with the help of special adaptations acting on basis of materials linear expansion factors difference. The optimum welding mode is determined experimentally.

The electron-optical system of beam formation provides a uniform distribution of current density over the output window and the cathode surface. Cathodes with flat emitting surface are used here.

A series of electron guns with various parameters was developed. The parameters of one of them with large average power of extracting beam are given in Table 3 .

\subsection{Use Efficiency of Low Energy Electron Beams}

In all radiating processes mentioned above the application of electron gun is represented rather effective because it forms intensive flow of low energy electrons at rather low

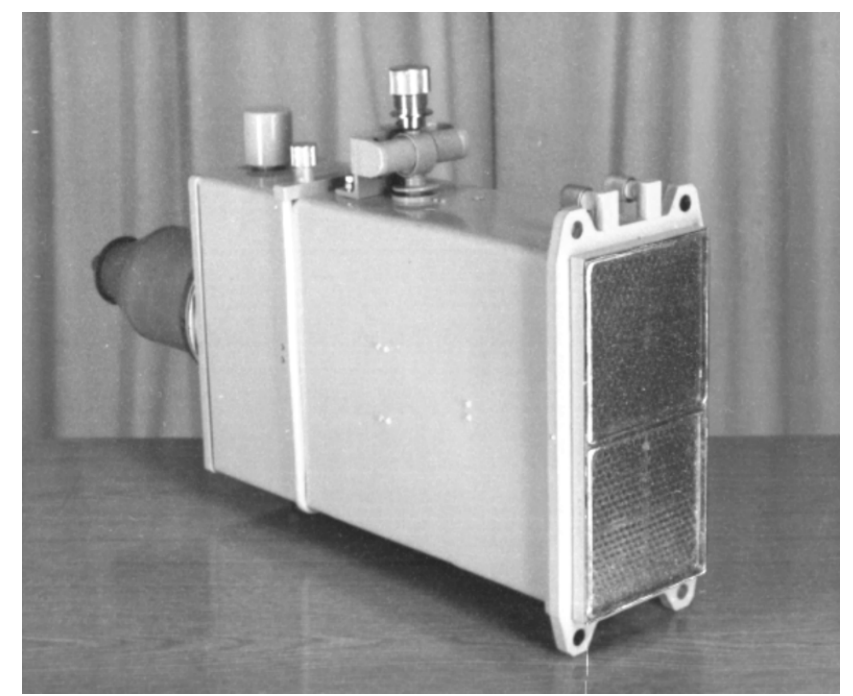

Figure 2: Appearance of the electron gun.

Table 3: Parameters of the Electron Gun with a High Average Power.

\begin{tabular}{|l|l|}
\hline Average beam power & $400 \mathrm{~W}$ \\
\hline Output window cross section & $200 \times 100 \mathrm{~mm}^{2}$ \\
\hline Electrons energy & $200 \mathrm{keV}(\mathrm{max})$. \\
\hline Cathode current & $80 \mathrm{~A}$ \\
\hline Output current & $10 \mathrm{~A}$ \\
\hline Surface absorbed doze rating & $300 \mathrm{kGr} / \mathrm{s}(\mathrm{max})$. \\
\hline Pulse duration & $5 \mu \mathrm{s}$ \\
\hline Pulse following frequency & $50 \mathrm{~Hz}$ \\
\hline Gun overall dimensions & $400 \times 230 \times 114 \mathrm{~mm}^{3}$ \\
\hline Gun mass & $20 \mathrm{~kg}$ \\
\hline
\end{tabular}

costs of the gun and its exploitation. The gun provides rather high dozes of irradiation, that allows to create highefficiency installations. For example, for optimum modification of the characteristics polyvinilchloride (PVC) the dozes of an irradiation of the order $20-30 \mathrm{kGr}$ are required. The area of a target window of a gun makes 0,02 $\mathrm{m}^{2}$. Then for 1 second can be processed $0,25 \mathrm{~m}^{2}$ of a surface of products from PVC or $900 \mathrm{~m}^{2}$ in one hour. For polythene with an optimum doze $\sim 50 \mathrm{kGr}$ the productivity of installation will make $400-450 \mathrm{~m}^{2} /$ hour. Thus power requirements on $1 \mathrm{~m}^{2}$ the surfaces will not exceed about $0,004 \mathrm{kWh}$ for PVC and - 0,008 kWh for polythene. 